\title{
Correction to: Energy-Balanced Routing Protocol with QoS Constraints in Ad Hoc Network
}

Lu Guo, Peng Li, Jiyu Jin, and Jun Mou

\section{Correction to:}

Chapter "Energy-Balanced Routing Protocol with QoS

Constraints in Ad Hoc Network" in: Q. Liang et al. (Eds.):

Communications, Signal Processing, and Systems 2018,

Lecture Notes in Electrical Engineering 515, 2019,

https://doi.org/10.1007/978-981-13-6264-4_117

In the original version of the book, the following belated correction has been incorporated: The author name "Filippo, M.D." has been changed to "Di Filippo, M." in reference (12). 